\title{
Effect of Dietary Selenium and Vitamin E Supplementation on Testicular Morphology and Serum Testosterone Concentration in Goats Following Scrotal Insulation*
}

\author{
Guadalupe Carvalho Xavier ${ }^{1}$, Pierre Castro Soares ${ }^{2}$, Valdemiro Amaro da Silva Junior ${ }^{2}$, \\ Sandra Maria de Torres ${ }^{2}$, Ana Cristina Marinho Maymone ${ }^{2}$, Rosana Nogueira de Morais ${ }^{3}$, \\ Cristiane Scavuzzi Moura ${ }^{2}$ \& Maria Madalena Pessoa Guerra²
}

\begin{abstract}
Background: Heat directly applied to the testis has been providing information regarding the damage triggering mechanisms on spermatogenesis and possible treatments to prevent testicular changes. Testis submitted to heat-shock have inhibition of the local antioxidant defense mechanisms against lipid peroxidation and free radicals. Vitamin E and Selenium protect biological membranes against free radicals to prevent membrane lipid peroxidation. The current assay evaluated the effect of dietary supplementation with Selenium and Vitamin E on testicular parenchyma and testosterone levels of goats submitted to heat shock by scrotal insulation. Materials, Methods \& Results: The effect of dietary selenium and vitamin E supplementation on testicular parameters and serum testosterone concentration was evaluated in goats subjected to scrotal insulation. The animals were randomly allocated into two groups $(n=6)$ to receive either a control diet $(\mathrm{CO})$ or a diet supplemented with selenium and vitamin $\mathrm{E}(\mathrm{SE})$. The animals received supplementation for 120 days: 60 days prior to scrotal insulation, 18 days during scrotal insulation and 42 days after scrotal insulation. Orchiectomy was performed on three animals from each group, immediately after the end of scrotal insulation. The remaining animals were neutered at the end of the experimental period (120 days). Testicles were routinely processed and embedded in glycol methacrylate, stained with toluidine blue/1\% sodium borate and evaluated qualitative and quantitatively. Serum testosterone concentrations were determined by enzyme immunoassay at the time of the orchiectomy. Scrotal circumference was greater $(P<0.05)$ in goats of the SE group $(23.0 \pm 1.00 \mathrm{~cm})$ than those of the control group $(20.0 \pm 1.00 \mathrm{~cm})$ at the end of the scrotal insulation period (Day 18). At the end of the experimental period (Day 42 post-scrotal insulation (PSI)), the seminiferous tubule diameter and seminiferous epithelium height were greater $(P<0.05)$ in the SE group than in control. Histological changes associated with testicular degeneration were detected after 18 days of scrotal insulation in the goats of the control group. The animals of SE group had some histological changes of seminiferous tubules but the majority of them had normal association of germ cells. Selenium and vitamin E supplementation did not seem to avoid testicular damage caused by scrotal insulation but accelerated testicular recovery after the removal of insulation. Testosterone serum levels were not changed in the animals submitted to scrotal insulation, with or without dietary supplementation with selenium and vitamin E.

Discussion: In the current study, scrotal insulation for 18 days caused testicular degeneration in both groups. However, selenium and vitamin E supplementation were capable of maintaining the scrotal circumference on the $18^{\text {th }}$ day of insulation in the $\mathrm{SE}$ group. Previous reports suggested that selenium and vitamin E could protect cell membranes against the harmful effects of reactive oxygen species. However, the histopathological changes and morphometric data observed in the both groups after 18 days of insulation demonstrated that supplementation with these antioxidants did not prevent the damage caused by heat stress. In turn, at 42 days after the removal of insulation, the tubular diameter and seminiferous epithelium height was greater in animals supplemented with selenium and vitamin E. In addition, the animals that received supplementation had most of seminiferous tubules with cell associations of the seminiferous epithelium cycle. Vitamin $\mathrm{E}$ and selenium may reduce testicle sensitivity to heat and thereby shorten the spermatogenesis recovery time by 10 to 20 days. Selenium plus vitamin E added to feed was unable to prevent the degeneration of the testicular parenchyma in these animals. Nonetheless, the supplementation with both antioxidants hastened the recovery of spermatogenesis after the thermal injury.
\end{abstract}

Keywords: thermal injury, testes, histopathology, Capra hircus, antioxidants.

"Article based on a Thesis submitted by the senior author in partial fulfillment of requirements for the Master's Degree. ${ }^{1}$ Serviço Nacional de Aprendizagem Rural (SENAR), Salvador, BA, Brazil. ' ${ }^{2}$ eppartamento de Medicina Veterinária, Universidade Federal Rural de Pernambuco (UFRPE), Recife, PE, Brazil. ${ }^{3}$ Departamento de Fisiologia, Universidade Federal do Paraná (UFPR), Curitiba, PR, Brazil. CORRESPONDENCE: M.M.P. Guerra [mmpguerra@ gmail.com - Tel: +55 (81) 33206412]. Departamento de Medicina Veterinária, Universidade Federal Rural de Pernambuco (UFRPE). Rua Dom Manoel de Medeiros, s/n. CEP 52171-900 Recife, PE, Brazil. 


\section{INTRODUCTION}

Testis exposure to heat can trigger testicular degeneration, which is defined as a process that causes deterioration of testis structure, resulting in the loss of testicular function [29]. Germ cells are vulnerable to heat stress and undergo apoptosis if scrotal temperatures rise above the normal physiological temperature range [9]. Heat directly applied to the testis has been providing new information regarding the damage triggering mechanisms on spermatogenesis and possible treatments to prevent damage to the testis by blocking apoptosis [27].

In humans, cryptorchidism [19] and varicocele [18] inhibit the local antioxidant defense mechanisms and cause lower sperm concentrations and fewer mobile sperm cells [2]. All cellular components are potential targets of oxidative stress and its damages depend on the nature and amount of reactive oxygen species (ROS) as well as on the duration of exposure, together with extracellular factors, such as temperature, oxygen tension and environment [1].

Selenium and vitamin E are distinct chemical elements with unique antioxidant characteristics in biological systems. Vitamin E (-tocopherol), the major lipid soluble antioxidant present in all cellular membranes, protects against lipid peroxidation [10]. Selenium is a major component of the glutathione peroxidase enzyme (GPx) which neutralizes peroxides before they attack the cell membrane [30].

The current assay evaluated the effect of selenium and Vitamin E supplementation on testicular parenchyma and testosterone levels of goats submitted to heat shock by scrotal insulation during 18 days.

\section{MATERIALS AND METHODS}

\section{Animals}

Twelve male mixed-breed goats, seven to eight months old, were selected following a breeding soundness examination. The animals were randomly allocated into two groups $(n=6)$ to receive either a control diet (CO) or a diet supplemented with selenium and vitamin $\mathrm{E}$ (SE). All animals were kept in pens and fed with Tifton grass and balanced feed (corn and soy bean; $200 \mathrm{~g} / \mathrm{animal} / \mathrm{day}$ ). The balanced feed contained $87.2 \%$ dry matter, $17.8 \%$ crude protein, $9.75 \mathrm{ME} / \mathrm{kg}$ metabolizable energy, $0.41 \%$ calcium and $0.32 \%$ phosphorus. The animals also had free access to mineral salt (to meet $\mathrm{Ca}$ and $\mathrm{P}$ needs) and water.
Animals in the SE group were supplemented with selenium $(0.1 \mathrm{mg} / \mathrm{kg} \mathrm{BW})$ and vitamin $\mathrm{E}(0.3 \mathrm{UI} /$ $\mathrm{kg} \mathrm{BW}$ ) [Selevit E] $]^{1}$ from 60 days before the scrotal insulation until the end of the experiment. Prior to the scrotal insulation, all animals were weekly weighed to ensure a linear relation between body weight gain and daily supplementation with selenium and vitamin $E$ in the SE group. Insulation comprised the enveloping of the scrotum in a plastic bag containing two sheets of polyethylene separated by a 5-mm thick layer of cotton [5]. The plastic bag covered all testicular parenchyma and was fixed at the spermatic cord region, close to the abdominal wall, whose circumference was adjusted with a ribbon according to the diameter of the spermatic cord of each animal, to ensure the constant position of the plastic bags. The plastic bags were observed daily to avoid any position variation during the experiment. The temperature of the scrotal surface was daily measured using a thermometer inserted in the space between the plastic bag and the testis. All animals remained with the plastic bag during the 18 days of scrotal insulation. On Day 18 (scrotal insulation=Day 0), three animals from each group were randomly selected for bilateral orchiectomy. The remaining animals continued to receive control or supplemented diets for another 42 days (until Day 60), when bilateral orchiectomy was also performed.

\section{Testicular parameters}

Scrotal circumference was measured before and after scrotal insulation with a metric tape placed around the middle section of both testes. After orchiectomy, the testis were separated from the epididymis and weighed. Six samples were taken from different parts of the organ near the albuginea tunica. The gonadosomatic index (GSI\%) was established by the following formula: GSI=(Testis weight/body weight) $\mathrm{x}$ 100 . The parameter is applied to determine the quantity of overall body mass allocated to the testis.

All testicular fragments ( $2 \mathrm{~mm}$ in thickness) were fixed in Phosphate Buffered Saline (PBS) solution containing $4 \%$ glutaraldehyde $(\mathrm{pH} 7.2$ and $0.01 \mathrm{M}$ ). The tissue fragments were routinely processed for embedding in glycol methacrylate ${ }^{2}$, sectioned ( $4 \mu \mathrm{m}$ thick) and stained with toluidine blue/1\% sodium borate. Seminiferous tubule diameter and epithelium height were measured with a linear micrometric reticulum $^{3}(10 \mathrm{~mm} / 100)$ magnified $100 \mathrm{X}$ and calibrated with a standard micrometer. Fifteen 
round or almost round tubules per testis/animal at different stages of the seminiferous epithelium cycle were randomly selected for measurement. Thirty seminiferous epithelium heights per testis/animal were measured in the same tubules used for the measurement of the tubular diameter.

The volumetric density (\%) of the testicular parenchyma was obtained with the systematic allocation of the micrometric grid $^{3}$, with 441 intersections points over the testicular parenchyma, under $400 \mathrm{X}$ magnification. Fifteen randomly selected fields were examined, totaling 6,615 for each animal. The volume of the tunica propria, seminiferous epithelium and lumen was evaluated in the tubular compartment, whereas the volume of Leydig cells, connective tissues and blood and lymphatic vessels were evaluated within the interstitial compartment. Since testis density varied between 1.03 and 1.04 [8], weight and volume of the testes were considered equal. The volume of each testicular component (expressed in $\mathrm{mL}$ ) was determined by subtracting the volumetric density of the testicular components (\%) from the net weight of the testis (testicular weight minus the weight of the albuginea and testicular mediastinum) [25]. The total length of seminiferous tubules for each testis was calculated based on the volume and diameter of the seminiferous tubules, by the formula: $\mathrm{TL}=\mathrm{TVS} / \omega \mathrm{R}^{2}$, in which TVS is the total volume of the seminiferous tubules and $\mathrm{R}$ is the tubular diameter/2 [4].

Histopathological changes in the testicular tubular compartment were also taken into account. They comprised epithelial desquamation, necrosis and apoptosis of germ cells, syncytial giant cells and macrophages, Sertoli cell vacuolization, and the thickening of the basal membrane. The presence or absence of inflammatory cells, Leydig cell degeneration and vascular changes were analyzed in the interstitial or intertubular compartment. The stages of the seminiferous cycle were evaluated at different steps following scrotal insulation. The main objective was to determine whether selenium plus vitamin $\mathrm{E}$ influenced the recovery of the spermatogenic process after 18 days of scrotal insulation or whether it inhibited the tubular degeneration.

\section{Testosterone concentrations}

Blood samples were collected immediately prior to scrotal insulation (Day 0), at the end of in- sulation removal (Day 18) and after 7, 21, 35 and 42 days following the cessation of insulation. Blood was drawn from the jugular vein, collected in a vacuum container without any anticoagulant and centrifuged (1000 $\mathrm{g}$ for $10 \mathrm{~min}$ ). The serum was separated and stored $\left(-20^{\circ} \mathrm{C}\right)$ until analysis. Serum testosterone concentrations were determined by enzyme immunoassay [21] with a polyclonal antibody raised against human testosterone (R156/7) 4 in a dilution 1:7500 and testosterone HRP conjugate at 1:20,000. Validation of the method for goats was performed beforehand by demonstrating parallelism between the standard curve and the curve generated by a pool of all the goat serum samples to be analyzed, diluted serially from $1: 1$ to 1:128 with EIA buffer [0.04 M sodium phosphate (monobasic, monohydrate), $0.06 \mathrm{M}$ sodium phosphate (dibasic), $0.87 \% \mathrm{NaCl}$ and $0.1 \% \mathrm{BSA}, \mathrm{pH} 7.0]$. The dilutions closest to $50 \%$ of binding (1:2 or $1: 4)$ were used for assaying the samples. Standards were run in triplicate, while control and samples were done in duplicate. Assay sensitivity was $78 \mathrm{ng} / \mathrm{mL}$ and the intra-assay and inter-assay coefficients of variations were $5.1 \%$ and $3.5 \%$, respectively. After adjustment for the dilution factor, testosterone concentration was expressed as $\mathrm{ng} / \mathrm{mL}$.

\section{Statistical Analysis}

Data were submitted to variance of analysis (ANOVA) for repeated measures, which considered the effect of treatment, the sample collection time and interaction of the two as the cause of variation. The level of significance $(P)$ was set at $5 \%$. The minimum significant difference (MSD) of the Student-NewmanKeuls test compared averages when significant results were detected. Data analysis was performed by the Statistical Analysis System [26].

\section{RESULTS}

The temperature of the inner plastic bag varied between 39 and $40^{\circ} \mathrm{C}$. The scrotal circumference was $12.3 \%$ minor $(P<0.05)$ at day 18 in the $\mathrm{CO}$ group when compared with day zero at the same group. This parameter was greater $(P<0.05)$ in goats of the SE group $(23.0 \pm 1.00 \mathrm{~cm})$ than of the control group $(20.0$ $\pm 1.00 \mathrm{~cm}$ ) at the end of the scrotal insulation period (Day 18), but no differences were detected at the end of the experiment [Day 42 PSI; $22.17 \pm 0.76 \mathrm{~cm}$ and $22.3 \pm 1.53 \mathrm{~cm}$ in $\mathrm{SE}$ and $\mathrm{CO}$ groups, respectively] (Table 1). 
Table 1. Mean, standard deviation and significance $(P)$ values for scrotal circumference prior to scrotal insulation (SI) and end of post-scrotal insulation (PSI) period in goats with and without dietary supplementation of selenium and vitamin E.

\begin{tabular}{ccccc}
\hline \multirow{2}{*}{ Group } & \multicolumn{3}{c}{ Days } & Day 42 PSI \\
\cline { 2 - 4 } & Day 0 & Day 18 SI & $22.33 \pm 1.53^{\mathrm{Aab}}$ & 0.020 \\
CO & $22.80 \pm 0.99^{\mathrm{Aa}}$ & $20.00 \pm 1.00^{\mathrm{Bb}}$ & $22.17 \pm 0.76^{\mathrm{A}}$ & 0.709 \\
\hline SE & $23.00 \pm 1.82^{\mathrm{A}}$ & $23.00 \pm 1.00^{\mathrm{A}}$ & 0.874 & \\
\hline$P$-value & 0.773 & 0.021 &
\end{tabular}

$\mathrm{CO}=\mathrm{Control}$ group; $\mathrm{SE}=$ Selenium and vitamin E group; Different capital letters in same column differ at level of 5\%; Different lowercase letters in the same line differ at level of $5 \%$.

Selenium and vitamin E supplementation had no effect on body weight, testicular weight, epididymal weight or gonadosomatic index $(P>0.05)$ [Table 2]. After scrotal insulation (Day 18), only the volume of the testicular parenchyma occupied by blood vessels was greater $(P<0.05)$ in the SE group than in control.
However, at the end of the experimental period (Day 42 PSI; Table 2), the volume of the parenchyma occupied by seminiferous tubules and seminiferous epithelium as well as seminiferous tubule diameter and seminiferous epithelium height were greater $(P<0.05)$ in the SE group than in control.

Table 2. Mean and standard deviation values of biometric parameters of testis and epididymis, net testicular weight, volumetric and biometric parameters of testicular parenchyma in goats submitted to scrotal insulation (SI) with and without dietary supplementation with selenium and vitamin E after scrotal insulation period (Day $18 \mathrm{SI}$ ) and at end of post-scrotal insulation (Day $42 \mathrm{PSI}$ ) period.

\begin{tabular}{|c|c|c|c|c|}
\hline \multirow{3}{*}{ Parameter } & \multicolumn{2}{|c|}{$\begin{array}{c}\text { Immediately post-scrotal insulation } \\
\text { period (Day } 18 \mathrm{SI})\end{array}$} & \multicolumn{2}{|c|}{$\begin{array}{c}\text { Recovery of scrotal insulation perioc } \\
\text { (Day } 42 \text { PSI) }\end{array}$} \\
\hline & \multicolumn{2}{|c|}{ Experimental Groups } & \multicolumn{2}{|c|}{ Experimental Groups } \\
\hline & $\mathrm{CO}^{*}$ & $\mathrm{SE}^{* *}$ & $\mathrm{CO}$ & SE \\
\hline Body weight (kg) & $27.180 \pm 4.74$ & $23.750 \pm 2.08$ & $25.290 \pm 2.17$ & $23070 \pm 1.50$ \\
\hline Testicular weight $(\mathrm{g})$ & $44.63 \pm 10.25$ & $63.00 \pm 3.24$ & $55.10 \pm 5.56$ & $55.60 \pm 10.87$ \\
\hline Epididymal weight (g) & $8.47 \pm 0.84$ & $9.90 \pm 1.28$ & $8.47 \pm 2.08$ & $7.83 \pm 1.27$ \\
\hline $\operatorname{GSI}(\%)^{1}$ & $0.16 \pm 0.01$ & $0.26 \pm 0.01$ & $0.22 \pm 0.36$ & $0.25 \pm 0.06$ \\
\hline Net testicular weight (g) & $38.23 \pm 9.38$ & $55.76 \pm 3.26$ & $49.07 \pm 4.72$ & $50.43 \pm 10.42$ \\
\hline Seminiferous tubule (mL) & $29.87 \pm 7.01$ & $42.20 \pm 2.76$ & $38.85 \pm 1.47$ & $40.13 \pm 8.23$ \\
\hline Seminiferous epithelium (mL) & $24.04 \pm 6.29$ & $33.30 \pm 3.40$ & $29.75 \pm 1.19$ & $30.78 \pm 6.24$ \\
\hline Tubular lumen $(\mathrm{mL})$ & $3.01 \pm 0.66$ & $5.62 \pm 0.96$ & $6.71 \pm 2.55$ & $7.68 \pm 2.90$ \\
\hline Tunica propria $(\mathrm{mL})$ & $2.80 \pm 0.47$ & $3.28 \pm 1.05$ & $2.39 \pm 0.37$ & $1.67 \pm 0.17$ \\
\hline Leydig cell (mL) & $1.49 \pm 0.48$ & $2.29 \pm 0.13$ & $1.70 \pm 0.24$ & $1.75 \pm 0.24$ \\
\hline Connective cells (mL) & $0.10 \pm 0.07$ & $0.30 \pm 0.07$ & $0.07 \pm 0.03$ & $0.13 \pm 0.03$ \\
\hline Blood vessels $(\mathrm{mL})$ & $0.63 \pm 0.43$ & $0.65 \pm 0.07$ & $0.30 \pm 0.12$ & $0.48 \pm 0.13$ \\
\hline Lymphatic space (mL) & $6.17 \pm 1.88$ & $10.33 \pm 1.96$ & $8.15 \pm 3.32$ & $7.94 \pm 2.10$ \\
\hline Seminiferous tubular diameter $(\mathrm{mm})$ & $295.52 \pm 22.01$ & $305.01 \pm 22.68$ & $330.52 \pm 30.43^{\mathrm{b}}$ & $339.34 \pm 3.35^{\mathrm{a}}$ \\
\hline Seminiferous epithelium height (mm) & $103.00 \pm 15.87$ & $101.00 \pm 14.42$ & $82.13 \pm 61.85^{\mathrm{b}}$ & $112.23 \pm 7.41^{\mathrm{a}}$ \\
\hline $\operatorname{TLST}(\mathrm{m})^{2}$ & $430.43 \pm 45.85$ & $581.90 \pm 71.01$ & $460.13 \pm 80.74$ & $444.30 \pm 95.52$ \\
\hline
\end{tabular}

${ }^{*} \mathrm{CO}=$ Control group; ${ }^{* *} \mathrm{SE}=$ Selenium and vitamin E group; ${ }^{1} \mathrm{GSI}=$ Gonadosomatic index; ${ }^{2} \mathrm{TLST}=$ Total length of seminiferous tubule; Different lowercase letters on same line denote significant difference between groups in each scrotal insulation period $(P<0.05)$.

Histological changes associated with testicular degeneration were detected after 18 days of scrotal insulation in the goats of the control group. A reduction in the epithelium due to degeneration caused by germinative cell desquamation (Figure 1a), which, in turn, caused the obliteration of the lumen of the seminiferous tubules, as well as syncytial giant cells and macrophages (Figure 1b), were observed in the seminiferous tubules. The following alterations were also observed: vacuolization of Sertoli cells and thickening of the basal membrane (Figures 1a and 1b); clusters of Leydig cells, with fatty degeneration (Figure 1c); or necrosis (Figure 1d). Although similar changes were reported in the goats of the SE group (Figures 1e, 1f, 1g and 1h), seminiferous tubules containing cell associations characteristic of normal stages of the seminiferous epithelium cycle were also observed in the animals (Figure 1f). 

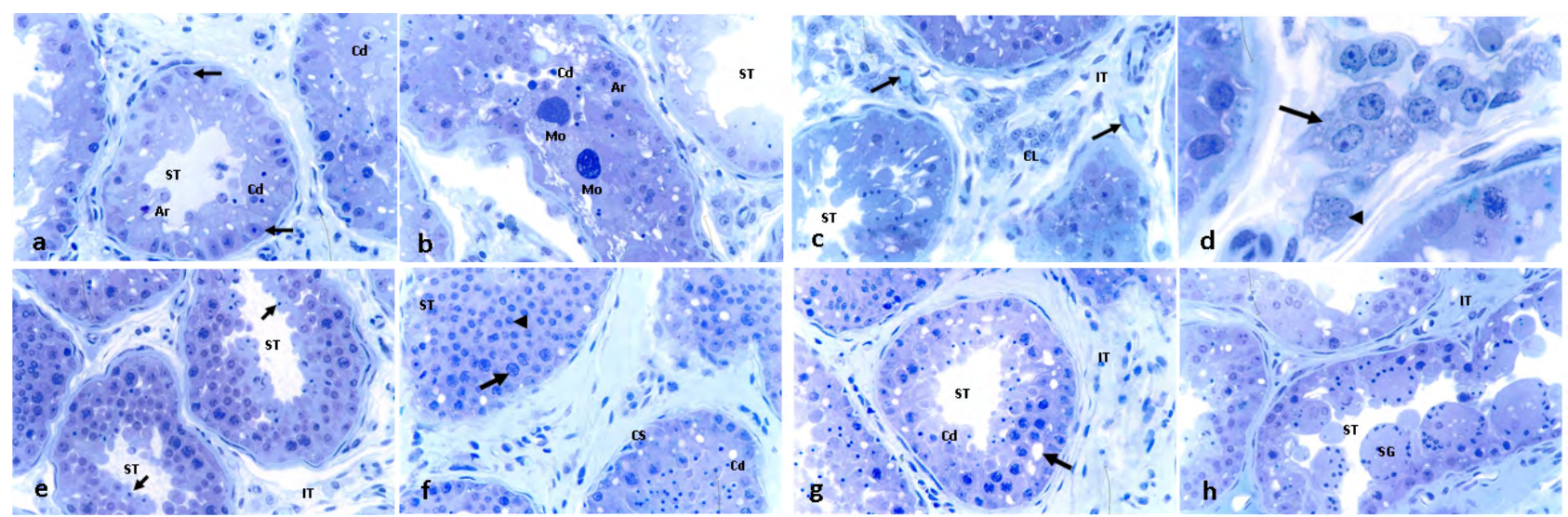

Figure 1. Testis of goats supplemented or not with SE on Day 18 following of scrotal insulation. a- Cross section of seminiferous tubule (ST) of goats in control group; rounded spermatids and desquamation of germinative epithelium (Ar); germ cell dead (Cd); Sertoli cells (arrow) and seminiferous tubules with germ cell dead [bar $=35 \mu \mathrm{m}]$. b- Testicular parenchyma of goats of control group; seminiferous tubules (ST) with atrophy of germinative epithelium; seminiferous tubule containing germ cell dead (Cd), aggregates of rounded spermatids and presence of macrophages $(\mathrm{Mo})$ [bar $=35 \mu \mathrm{m}]$. c- Testicular parenchyma of goats of control group; Cross section of seminiferous tubules with atrophy of germinative epithelium and germ cell dead (Cd); blood vessels (arrow) and agglomerate of Leydig cells (LC); intertubule (IT) $[\mathrm{bar}=35 \mu \mathrm{m}]$. d- Detailed image of agglomerate of Leydig cells of goat of control group; cells with vacuolization (arrow), necrosis (star) and cariolysis of nucleus (arrow head) $[\mathrm{bar}=70 \mu \mathrm{m}]$. e- Cross section of seminiferous tubules (ST) of goats treated with SE; tubules with germinative epithelium containing few desquamated and (arrow) germ cell dead; intertubule (IT) [bar $=35 \mu \mathrm{m}]$. f- Cross section of seminiferous tubules (ST) of goats treated with SE; seminiferous tubule (ST) in Stage I of seminiferous epithelium cycle; spermatocytes in pachytene (arrow) and rounded spermatids (arrow head); seminiferous tubule containing vacuolized Sertoli cells (SC) and germ cell dead (Cd) [bar $=35 \mu \mathrm{m}]$. g- Cross section of seminiferous tubules (ST) of goat treated with SE; germ cell dead (Cd) and vacuolized Sertoli cells (arrow); intertubule (IT) [bar $=35 \mu \mathrm{m}]$. h- Cross section of seminiferous tubules (ST) of goats treated with SE; longitudinal section of seminiferous tubule containing syncytial giant dead cells $(\mathrm{SG})[\mathrm{bar}=35 \mu \mathrm{m}]$.

At the end of the experimental period (Day 42 PSI), partial regeneration was registered in the goats of the control group. It included the atrophy of seminiferous tubules, reduced tubular diameter, thinned germinative epithelium and tubules obliterated with degenerated and desquamated germinative cells (Figures 2a, 2b, 2c and 2d). Germ cells desquamated, Sertoli cells vacuolated and thickening of the basal membrane (Figures $2 \mathrm{~b}$ and $2 \mathrm{~d}$ ) were also reported in some tubules.
Contrastingly, seminiferous tubules containing round and elongated spermatids and seminiferous tubules at Stages I and VIII of the seminiferous epithelium cycle were observed in the goats of the SE group at the end of the experimental period (Figures 2e, 2f, $2 \mathrm{~g}$ and $2 \mathrm{~h}$ ).

The testosterone serum levels (Table 3) were not changed in the animals submitted to scrotal insulation in either the non-supplemented or the vitamin $\mathrm{E}$ and Selenium-supplemented groups.
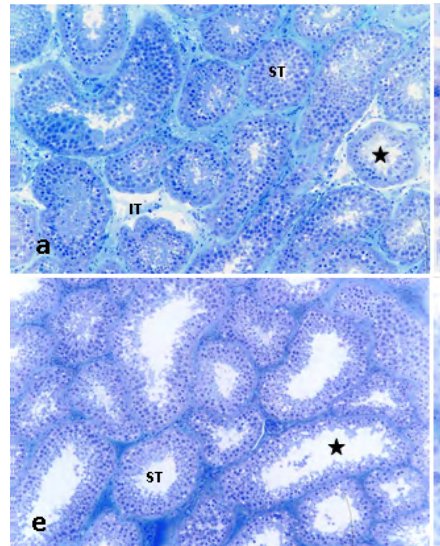
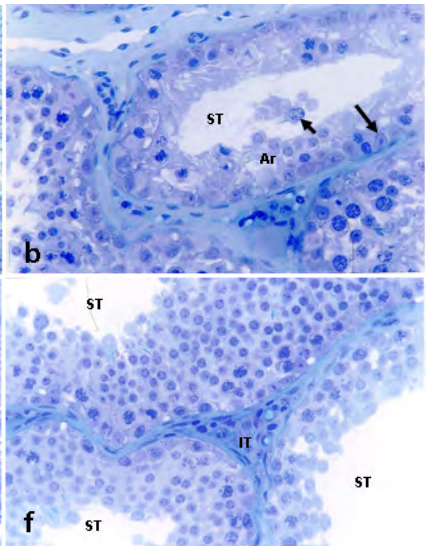
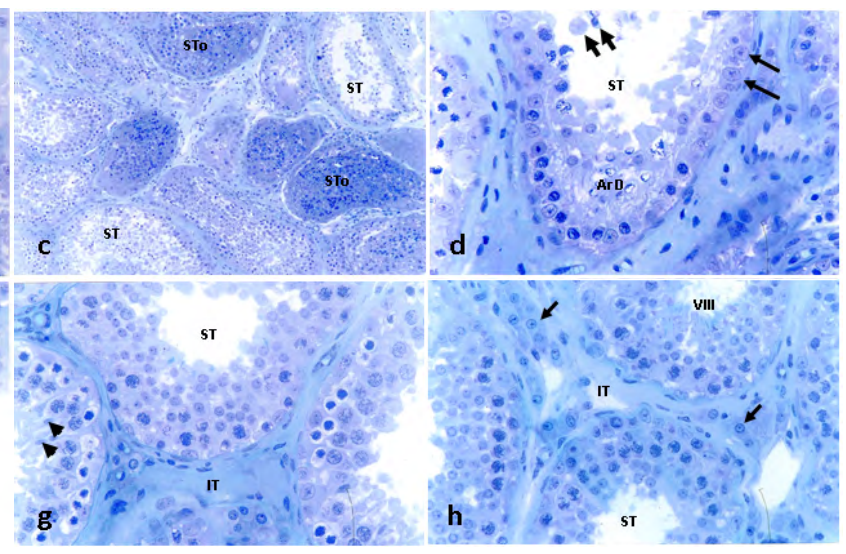

Figure 2. Testis of goats supplemented or not with SE on Day 42 after cessation of scrotal insulation. a- Cross section of testicular parenchyma of goats of control group; seminiferous tubules (ST) with smaller diameter and atrophy of germinative epithelium (asterisk); intertubule (IT) [bar $=7 \mu \mathrm{m}]$. b- Cross section of seminiferous tubule (ST) of goats of control group; seminiferous tubules with atrophy of germinative epithelium; longitudinal section of seminiferous tubule with germ cell dead (arrow), desquamated rounded spermatids (Ar) and vacuolized Sertoli cells (black arrow) $[$ bar $=35 \mu \mathrm{m}]$. c- Testicular parenchyma of goats of control group; cross section of seminiferous tubules (ST) with desquamated germinative cells; lumen obstructed by large number of desquamated and degenerated cells (STo); intertubule (IT) [bar $=7 \mu \mathrm{m}]$. d- Cross section of seminiferous tubule (ST) of goats of control; longitudinal section of seminiferous tubule containing desquamated cells (short arrow) and rounded degenerated spermatids (ArD); vacuolized Sertoli cells in basal compartment (long arrow) [bar $=35 \mu \mathrm{m}]$. e- Testicular parenchyma of goats treated with SE; cross section of seminiferous tubules with normal tubular diameter and normal epithelium height; atrophy of germinative epithelium and desquamated cells (asterisk) [bar $=7 \mu \mathrm{m}$ ]. f- Seminiferous tubules of goats treated with SE; tubules in Stage I of seminiferous epithelium cycle (ST); normal cell association characteristic of this stage; intertubule (IT) [bar $=70 \mu \mathrm{m}]$. g- Cross section of seminiferous tubules (ST) of goats treated with SE; seminiferous tubules (ST) in Stage I of seminiferous epithelium cycle; normal cell association characteristic of this stage; adjacent seminiferous tubule in Stage II with elongated spermatids (arrow head) and degenerated spermatocytes I in zygotene (arrows); intertubule (IT) [bar $=35 \mu \mathrm{m}]$. h- Cross section of seminiferous tubules (ST) of goats treated with SE; seminiferous tubules in Stage I and VIII of seminiferous epithelium cycle; normal Leydig cells in intertubule area (arrow) [bar $=35 \mu \mathrm{m}]$. 
Table 3. Mean and standard deviation values of serum testosterone concentration (ng/mL) before and at end of scrotal insulation period (SI) and postscrotal insulation period (Day 42 PSI) in goats submitted to scrotal insulation with and without dietary supplementation with selenium and vitamin E

\begin{tabular}{cccccccc}
\hline & \multicolumn{7}{c}{ Days } \\
\cline { 2 - 7 } Groups & Day 0 & Day 18 SI & Day 7 PSI & Day 21 PSI & Day 35 PSI & Day 42 PSI & P -value \\
& $\mathrm{n}=12$ & $\mathrm{n}=12$ & $\mathrm{n}=6$ & $\mathrm{n}=6$ & $\mathrm{n}=6$ & $0.83 \pm 0.47$ & 0.97 \\
\hline $\mathrm{CO}^{*}$ & $0.84 \pm 0.76$ & $0.64 \pm 0.48$ & $1.86 \pm 1.44$ & $1.24 \pm 0.95$ & $1.74 \pm 0.30$ & $0.87 \pm 0.33$ & 0.72 \\
\hline $\mathrm{SE}^{* *}$ & $0.60 \pm 0.26$ & $1.06 \pm 1.30$ & $1.49 \pm 1.49$ & $0.85 \pm 0.26$ & $0.33 \pm 0.06$ & 0.87 \\
\hline$P$-value & 0.51 & 0.83 & 1.68 & 0.63 & 0.96 & 0.85 \\
\hline
\end{tabular}

*CO= Control group; **SE= Selenium and vitamin E group.

\section{DISCUSSION}

Heat applied directly on the testis provides insight on spermatogenesis damage mechanisms and treatments to diminish or even prevent these lesions [27]. Although the scrotal insulation during 18 days had caused testicular degeneration in the CO and SE groups, selenium and vitamin E supplementation was capable of maintaining the scrotal circumference on the 18 th day of insulation in the SE group. In fact, vitamin $\mathrm{E}$ and selenium can reduce or even prevent damage caused by ROS in the testes submitted to heat shock and toxic agents [27,31]. The scrotal circumference has a direct relation to daily sperm production [17], Sertoli cell index and seminiferous tubule area and an inverse relation with germ cell degeneration rate [13]. It may be presumed that at the end of the scrotal insulation period (Day 18), the seminiferous tubular diameter and epithelium height would be greater in the SE group than the $\mathrm{CO}$ group. However, in current study, the morphometric and histopathological results revealed that supplementation with selenium and vitamin $E$ failed to reduce the effects of heat shock induced by scrotal insulation. Furthermore, there were no significant differences in tubular diameter and height of the seminiferous epithelium between the two groups. Selenium and vitamin E may protect cell membranes against the harmful effects of ROS [3]. In the present study, pathological changes observed in the animals of both groups after scrotal insulation demonstrated that supplementation with these antioxidants did not prevent the damage caused by heat stress.

The testicular data that characterize degenerative process were similar to those described by Rockett et al. [23], who reported germinative epithelium degeneration due to germ cell necrosis and apoptosis. The mechanism of cell death related to heat shock stress should be apoptosis rather than necrosis and may involve ROS [27]. In the current study, 42 days after removal of scrotal insulation, the tubular diameter and seminiferous epithelium height was greater in animals supplemented with selenium and vitamin E. In addition, the animals supplemented had more seminiferous tubules with germ cell associations of the seminiferous epithelium cycle than animals of the $\mathrm{CO}$ group.

Tubular diameter and epithelium height reflect different levels of activity of the seminiferous epithelium which may be related to seasonal changes [14], ageing [16], unbalance of endogenous or exogenous gonadotrophic hormones [28] and temperature increase [23]. These biometric parameters are important to evaluate the sperm production since there is a positive correlation between tubular diameter and spermatogenic activity [7]. Despite the ineffectiveness of the antioxidants selenium and vitamin $\mathrm{E}$ to avoid testicular degeneration caused by scrotal insulation, the supplementation at the dose used $(0.1 \mathrm{mg} / \mathrm{kg})$ accelerated seminiferous epithelium recovery after insulation.

In the current study, the changes observed in the Leydig cells were similar to those described by other authors [20] in cryptorchidic boars, in which degeneration and necrosis were characterized by intracellular vacuoles, pyknotic nucleus, karyolysis and karyorrhexis. These authors also described intertubular fibrosis as well as anomalous and degenerated Leydig cells.

The dietary mineral element selenium is essential for antioxidant protection and disease prevention since it functions as a component of the glutathione peroxidase enzyme (GPx), which destroys peroxides before they attack the cell membrane. Vitamin E acts as an antioxidant that interrupts the lipid peroxidation cascade and eliminates ROS to protect these cells from damage [11] as well as the glutathione peroxidase, whose major role is the removal of hydrogen peroxide and lipid peroxides from the cells [24]. Therefore, selenium and vitamin E could act synergistically to reduce Leydig cells damage of the SE group at the $18^{\text {th }}$ and $42^{\text {th }}$ day. 
After thermal exposure, the complete recover of the seminiferous epithelium may occur at 60 days [12]. However, azoospermia has occurred when heat shock affect spermatogonia [6]. Therefore, the recovery of the spermatogenesis after thermal stress depends on the survival of the spermatogonium A0 and Sertoli cells. Although semen samples were not collected in current study for sperm analysis, the histopathological evaluation revealed that 42 days after the thermal injury, animals supplemented with selenium and vitamin $\mathrm{E}$ had seminiferous tubules within round and elongated spermatids (Figure $2 \mathrm{~h}$ ) as well as all the stages of the seminiferous epithelium cycle. Vitamin $E$ and selenium may reduce testicle sensitivity to heat and thereby shorten the spermatogenesis recovery time by 10 to 20 days [27].

The literature is unclear on the association between testosterone concentration and heat shock. It was reported that the thermal stress caused by cryptorchidism induced an increase in testosterone levels, and thereby characterized an endocrine alteration in the testicular function in rats [22]. Wild-type mice submitted to heat shock had an increased number of Leydig cells surrounding seminiferous tubules with a reduction of germ cells [15]. According to the results of the current study, thermal stress did not alter serum testosterone levels in the animals of either groups during or after scrotal insulation. Degeneration and necrosis of Leydig cells was observed in all groups, mainly during the period of scrotal insulation.

To our knowledge, this is the first study on the supplementation with selenium and vitamin $\mathrm{E}$ in goats submitted to scrotal insulation, with a subsequent analysis after the cessation of thermal injury.

\section{CONCLUSION}

Selenium plus vitamin E added to feed was unable to prevent the degeneration of the testicular parenchyma in these animals. However, the supplementation with both antioxidants hastened the recovery of spermatogenesis after the thermal injury.

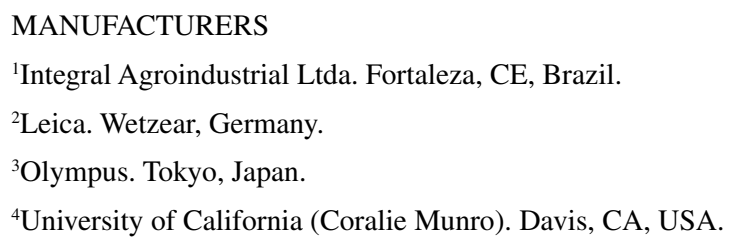

Acknowledgments. The authors are grateful to Integral Agroindustrial LTDA for sending the Selevit E and the Brazilian fostering agency CAPES for the Master's degree scholarship awarded to the first author.

Ethical approval. All procedures, treatments and animal care were approved by the Committee of Ethics in Research of the Departamento de Medicina Veterinária da Universidade Federal Rural de Pernambuco, process number: 88/2006.

Declaration of interest. The authors declare that they have no competing interests.

\section{REFERENCES}

1 Agarwal A., Saleh R.A. \& Bedaiwy M.A. 2003. Role of reactive oxygen species in the pathophysiology of human reproduction. Fertility and Sterility. 79: 829-843.

2 Aziz N., Saleh R.A., Sharma R.K., Lewis-Jones Y., Esfandiari N., Thomas A.J. \& Agarwal A. 2004 Novel association between sperm reactive oxygen species production, sperm morphological defects, and the sperm deformity index. Fertility and Sterility. 81: 349-354.

3 Bensoussan K., Morales C.R. \& Hermo L. 1998. Vitamin E deficiency causes incomplete spermatogenesis and affects the structural differentiation of epithelial cells of the epididymis in the rat. Journal of Andrology. 19: 266-288.

4 Dorst V.J. \& Sajonski H. 1974. Morphometrische untersuchunhen am tubulussystem des schweinehodens während der postnatalen entwicklug. Monatsh Veterinarmed. 29: 650-652.

5 Florentino C.M., Reis J.C., Guerra M.M.P., Maia F.C.L. \& Coleto Z.F. 2003. Effect of the scrotal insulation time over the constituents of the caprine semen (Capra hircus, L) with no defined breed. Ciência Veterinária nos Trópicos. 6 : $39-45$.

6 Fonseca V. \& Chow L.A. 1995. Seminal Characteristics of Zebu bull on transitory testicular degeneration. Arquivo Brasileiro de Medicina Veterinária e Zootecnia. 47: 707-716.

7 França L.R. \& Russell L.D. 1998. The testis of domestic mammals. In: Martinez-Garcia F. \& Regadera J. (Eds). Male Reproduction: a multidisciplinary overview. Madrid: Churchill Livingstone, pp.198-219.

8 França L.R., Cardoso F.M. \& Castro A.C.S. 1991. Effect of puberty and sexual development on daily sperm production and epididymal sperm reserves of Piau boars. Animal Reproduction Science. 25: 183-190. 
9 Kumagai A., Kodama H., Kumagai J., Fukuda J., Kawamura K., Tanikawa H., Sato N. \& Tanaka T. 2002. Xanthine oxidase inhibitors suppress testicular germ cell apoptosis induced by experimental cryptorchidism. Molecular Human Reproduction. 8: 118-123.

10 Machlin L.J. \& Bendich A. 1987. Free radical tissue damage: protective role of antioxidant nutrients. The Faseb Journal. 1: 441-445.

11 Mather J.P., Saez J.M., Dray F. \& Haour F. 1983. Vitamin E prolongs survival and function of porcine Leydig cells in culture. Acta Endocrinolology. 102: 470-475.

12 McEntee M.C. 2002. Reproductive oncology. Clinical Techniques in Small Animal Practice. 17: 133-149.

13 Moura A.A. \& Erickson B.H. 1997. Age-related changes in peripheral hormone concentrations and their relationship with testis size and number of Sertoli and germ cells in beef bulls. Journal of Reproduction and Fertility. 111: 183-190.

14 Muñoz E.M., Fogal T., Dominguez S., Scardapane L., Guzman J., Cavicchia J.C. \& Piezzi R.S. 1998. Stages of the cycle of the seminiferous epithelium of the viscacha (Lagostomus maximul maximus). The Anatomical Record. 252: 8-16.

15 Nakai A., Suzuki M. \& Tanabe M. 2000. Arrest of spermatogenesis in mice expressing an active heat shock transcription factor. The EMBO Journal. 19(7): 1545-1554.

16 Nipken C. \& Wröbel K.H. 1997. A quantitative morphological study of age-related changes in the donkey testis in the period between puberty and senium. Andrologia. 29: 149-161.

17 Osinowo O.A., Marrie B.N. \& Ekpe G.A. 1992. Preliminary study of postnatal growth and reproductive tract development in Yankasa rams. Animal Reproduction Science. 27: 49-54.

18 Pasqualotto F.F., Sharma R.K., Nelson D.R., Thomas A.J. \& Agarwal A. 2000. Relationship between oxidative stress, semen characteristics, and clinical diagnosis in men undergoing infertility investigations. Fertility and Sterility. 73: 459-464.

19 Peltola V., Huhtaniemi I. \& Ahotupa M. 1995. Abdominal position of rat testis is associated with high levels of lipid peroxidation. Biology of Reproduction. 53: 1146-1150.

20 Pinart E., Bonet S. \& Briz M. 2001. Cytology of the interstitial in scrotal and abdominal testes of post-puberal boars. Tissue and Cell. 3: 8-24.

21 Pugh P.J., Jones T.H. \& Channer K.S. 2003. Acute haemodynamic effects of testosterone in men with chronic heart failure. European Heart Journal. 24: 909-915.

22 Ren L., Medan M.S., Ozu M., Li C., Watanabe G. \& Taya K. 2006. Effects of experimental cryptorchidism on sperm motility and testicular endocrinology in adult male rats. Journal of Reproduction and Development. 52: 219-228.

23 Rockett J.C., Mapp F.L., Garges J.B., Luft J.C., Mori C. \& Dix D.J. 2001. Effects of hyperthermia on spermatogenesis, apoptosis, gene expression and fertility in adult male mice. Biology of Reproduction. 65: 229-39.

24 Rover Júnior L., Höehr N.F., Vellasco A.P. \& Kubota L.T. 2001. Sistema antioxidante envolvendo o ciclo metabólico da glutationa associado a métodos eletroanalíticos na avaliação do estresse oxidativo. Quimica Nova. 24: 112-119.

25 Russell L.D., França L.R., Hess R. \& Cooke P. 1995. Characteristics of mitotic cells in developing and adult testes with observations on cell lineages. Tissue and Cell. 27: 105-128.

26 SAS Institute. 2000. SAS/STAT Procedure guide for computers. 6th edn. SAS Institute, Cary, NC, USA.

27 Setchell B.P. 2006. The effects of heat on the testes of mammals. Animal Reproduction. 3: 81-91.

28 Swalund D.J., N'Diaye M.R., Loseth K.J., Pryor J.L. \& Crabo B.G. 1995. Diverse testicular responses to exogenous growth hormone and follicle-stimulating hormone in prepuberal boars. Biology of Reproduction. 53: 749-757.

29 Turner R.M.O. 2007. Pathogenesis, diagnosis, and management of testicular degeneration in stallions. Clinical Techniques in Equine Practice. 6: 278-284.

30 Underwood E.J. \& Suttle N.F. 1999. The Mineral Nutrition of Livestock. 3rd edn. New York: CABI publishing, 614p.

31 Yeo J.E., Kim J.H. \& Kang S.K. 2008. Selenium attenuates ROS-mediated apoptotic cell death of injured spinal cord through prevention of mitochondria dysfunction; in vitro and in vivo study. Cellular Physiology and Biochemistry. 21: 225-238.

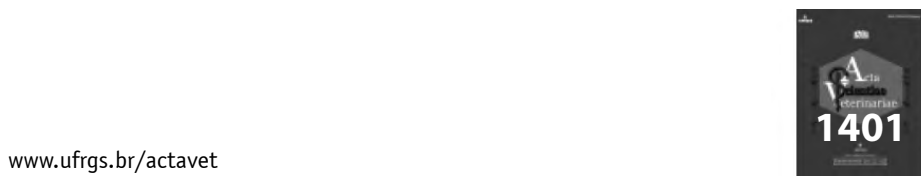

